\section{Measurement of the Oxidation Degree of Edible Fats and Oils by Direct Gas Chromatography}

\author{
Haruki Sano and Megumi YamazakI \\ National Food Research Institute, Ministry of \\ Agriculture and Forestry, Tokyo
}

Received May 21, 1976

Dupuy et al. reported an analytical method of volatiles from vegetable oils by direct gas chromatography and showed a possibility of following the degradation of vegetable oils upon aging. ${ }^{1)}$ Previously we reported that the amount of 2,4-decadienals which were obtained on a gas chromatogram of oxidized edible oils had a good correlation with peroxide values (P.O.V) and carbonyl values (C.V.), and that the oxidation degree of edible fats and oils could be measured by gas chromatography. This paper shows a simple, sensitive and rapid measurement of the oxidation degree of fats and oils by direct gas chromatography. ${ }^{2)}$

Soy bean oil and lard oxidized in an oven at $60^{\circ} \mathrm{C}$ were sampled at certain time intervals. Each $1 \mathrm{~g}$ sample was put into a $10 \mathrm{ml}$ volumetric flask, and $100 \mu 1$ of pentadecan solution $\left(1000 \mu \mathrm{g} / \mathrm{nl} \mathrm{CS}_{2}\right)$ was added as an internal standard, then filled up with $\mathrm{CS}_{2}$. From this solution $5 \mu \mathrm{l}$ was taken and analyzed by a Shimazu GC 4BPF gas chromatograph. Glass wool and glass beads were packed in the injection port of an $1 \mathrm{~m} \times 4 \mathrm{~mm}$ glass column as shown in Fig. 1. These were useable without exchange for more than 20 times measurements, and they were also easily exchangable.

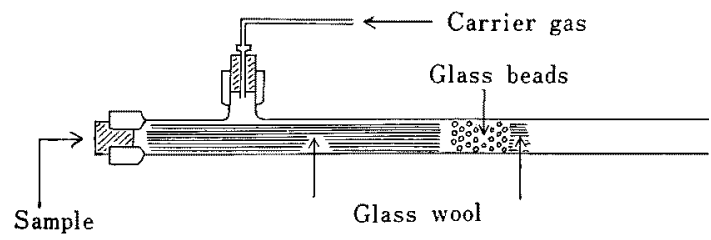

Frg. 1. Injection Port of Gas Chromatograph.

Gas chromatograms of oxidized lard and soy bean oil (0,7 and 11 days) are shown in Fig. 2. Main peaks $a$ and $b$ were identified as 2-trans-4-cis-decadienal and 2-trans-4-trans-decadienal respectively by the retention times of their gas chromatograms, gas chromatographic mass spectra and infrared spectra. The content of 2,4-decadienals was measured from the ratio of the peak areas of 2,4-decadienals and the internal standard on the gas chromatogram obtained. Peroxide values, carbonyl values and fatty acid compositions were measured according to the Standard of The Analytical Method. ${ }^{3)}$

The amounts of 2,4-decadienals, peroxide values and
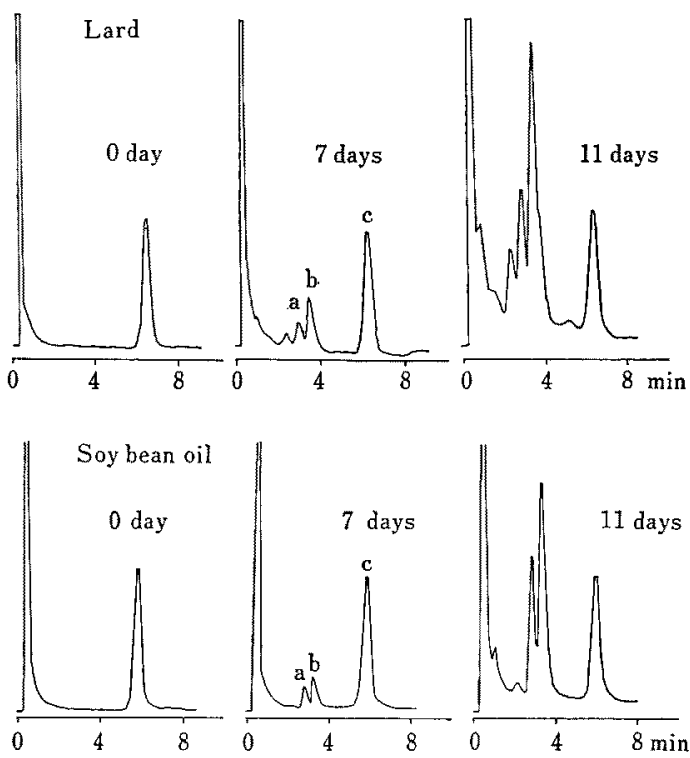

Fig. 2. Gas Chromatography of Oxidized Lard and Soy Bean Oil.

a, 2-trans-4-cis-decadienal

b, 2-trans-4-trans-decadienal

c, internal standard, pentadecan

Column: $3 \%$ Silicone OV-17 on Chromosorb W (AW-DMCS) $60 \sim 80$ mesh, $4 \mathrm{~mm} \times 1 \mathrm{~m}$ glass tube. Carrier gas $\mathrm{N}_{2} 40 \mathrm{ml} / \mathrm{min}$, column temp. $120^{\circ} \mathrm{C}$, injection temp. $250^{\circ} \mathrm{C}$.

Table I. Comparison of the Amount of 2,4Decadienals, Peroxide Value and Carbonyl VALUE IN OXIDIZED LaRd AND SOY BEAN OIL

\begin{tabular}{lcccc}
\hline & & $\begin{array}{c}\text { 2,4-Deca- } \\
\text { dienals } \\
(\mu / g \text { g oil })\end{array}$ & $\begin{array}{c}\text { P.O.V. } \\
\left(\begin{array}{c}\text { meq } / \mathrm{kg} \\
\text { oil })\end{array}\right.\end{array}$ & $\begin{array}{c}\text { C.V. } \\
(\text { O.D. }\end{array}$ \\
\hline Lard $)$
\end{tabular}


Table II. Fatty Acid Compositions of LaRd and Soy Bean OIL

\begin{tabular}{lllccccc}
\hline & $14: 0$ & $16: 0$ & $16: 1$ & $18: 0$ & $18: 1$ & $18: 2$ & $18: 3$ \\
\hline Lard & 2.0 & 25.0 & 3.7 & 9.1 & 45.4 & 13.9 & 0.9 \\
Soy bean oil & 0 & 11.5 & 0 & 2.1 & 21.4 & 58.8 & 6.2 \\
\hline
\end{tabular}

carbonyl values are compared in Table I. There seems to be a high degree of positive correlation among them. This gas chromatographic measurement required only $0.5 \mathrm{mg}$ of the sample oil, while P.O.V. required $1 \mathrm{~g}$ and $\mathrm{C} . \mathrm{V}$. required $50 \mathrm{mg}$, and it took less than $10 \mathrm{~min}$ for one analysis.

The fatty acid compositions of used lard and soy bean oil are shown in Table II. The proportions of linoleic acid were $13.9 \%$ for lard and $58.8 \%$ for soy bean oil. The rates of autoxidation of fatty acids and their esters depend on the difference in their degree of unsaturation, and the ratio of the autoxidation rates of methyl stearate (18:0): methyl oleate $(18: 1)$ : methyl linoleate $(18: 2)$ : methyl linolenate $(18$ : 3) is about 1:100:1000:2000.4) 2,4-Decadienals are the ones of the main oxidation products of linoleic acid and its esters. ${ }^{5)}$ Therefore this gas chromatographic measurement can be applied for fats and oils which are composed of linoleate esters to some extent.

We believe the determination of 2,4-decadienals can be used as a sensitive index of the oxidation degree of fats and oils by rapid and simple gas chromatographic method.

\section{REFERENCES}

1) H. P. Dupuy, S. P. Fore and L. A. Goldblatt, J. Amer. Oil Chem. Soc., 48, 876 (1971) and D. F. Brown, F. G. Dollen and H. P. Dupuy, ibid., 49, 81 (1972).

2) H. Sano and M. Yamazaki, Meeting of the Japan oil Chemists Society, Hiroshima, October 16, 1973.

3) Standard of The Analytical Method, Japan Oil Chemists Soc., 2.4.12-71, 2.4.22-73 and 2.4.21.273.

4) J. A. Howard and K. V. Ingold, Can. J. Chem., 45, 793 (1967).

5) W. Grosch, Z. Lebensm. Unters-Forsh., 157, 70 (1975). 